\title{
Review Article \\ Phytochemicals Mediated Remediation of Neurotoxicity Induced by Heavy Metals
}

\author{
Vivek Kumar Gupta, ${ }^{1}$ Shweta Singh, ${ }^{1}$ Anju Agrawal, ${ }^{2}$ \\ Nikhat Jamal Siddiqi, ${ }^{3}$ and Bechan Sharma ${ }^{1}$ \\ ${ }^{1}$ Department of Biochemistry, University of Allahabad, Allahabad 211002, India \\ ${ }^{2}$ Department of Zoology, SNBVPG College, CSJM University, Kanpur 208001, India \\ ${ }^{3}$ Department of Biochemistry, College of Science, P.O. Box 22452, King Saud University, Riyadh 11495, Saudi Arabia \\ Correspondence should be addressed to Bechan Sharma; sharmabi@yahoo.com
}

Received 31 July 2015; Accepted 15 October 2015

Academic Editor: Rona Ruth Ramsay

Copyright (C) 2015 Vivek Kumar Gupta et al. This is an open access article distributed under the Creative Commons Attribution License, which permits unrestricted use, distribution, and reproduction in any medium, provided the original work is properly cited.

\begin{abstract}
Almost all the environmental components including both the abiotic and biotic factors have been consistently threatened by excessive contamination of heavy metals continuously released from various sources. Different heavy metals have been reported to generate adverse effects in many ways. Heavy metals induced neurotoxicity and impairment in signalling cascade leading to cell death (apoptosis) has been indicated by several workers. On one hand, these metals are required by the cellular systems to regulate various biological functions of normal cells, while on the other their biomagnification in the cellular systems produces adverse effects. The mechanism by which the heavy metals induce neurotoxicity follows free radicals production pathway(s) specially the generation of reactive oxygen species and reactive nitrogen species. These free radicals produced in excess have been shown to create an imbalance between the oxidative and antioxidative systems leading to emergence of oxidative stress, which may cause necrosis, DNA damage, and many neurodegenerative disorders. This mini review summarizes the current knowledge available on the protective role of varied natural products isolated from different herbs/plants in imparting protection against heavy metals (cadmium, lead, arsenic, and mercury) mediated neurotoxicity.
\end{abstract}

\section{Introduction}

The heavy metals are generally characterized as the inorganic elements having specific gravity five times of water's specific gravity. Among many heavy metals listed into the dorbital elements of modern periodic table, arsenic, cadmium, mercury, and lead have got prime importance because of their pathophysiological significance as their bioaccumulation in living systems may cause severe damage to the vital organs, namely, nervous system and reproductive systems, gastrointestinal tract, and mucous tissues. Though the exact mechanism of their pathogenicity is not known but there are reports from various laboratories indicating that the exposure of these heavy metals or their excess accumulation in the body tissues may induce production of free radicals particularly the reactive oxygen species (ROS) and reactive nitrogen species (RNS) which finally culminate into production of oxidative stress $[1,2]$. Free radicals have been implicated into DNA damage, oxidation of thiol group(s) of proteins, and lipid peroxidation [3] which is associated to onset of various diseases.

Heavy metals reach into the environment from various sources such as from the crust of Earth mining and ground water, commercial products, industrial effluents, industrial wastes, vehicle emissions, lead-acid batteries, fertilizers, paints, treated woods, plastics floating on the world's oceans, and aging water supply infrastructure, folk remedies, and contaminated foods [2]. Thus heavy metals contaminate and intoxicate soil, water, and food items (agricultural and animal products). These elements may enter human systems through breathing, food or drink intake and contacts, and so forth. Upon accumulation, they induce various adverse effects in the body systems, characterized as heavy metals mediated toxicity. The present article is an endeavour to report 


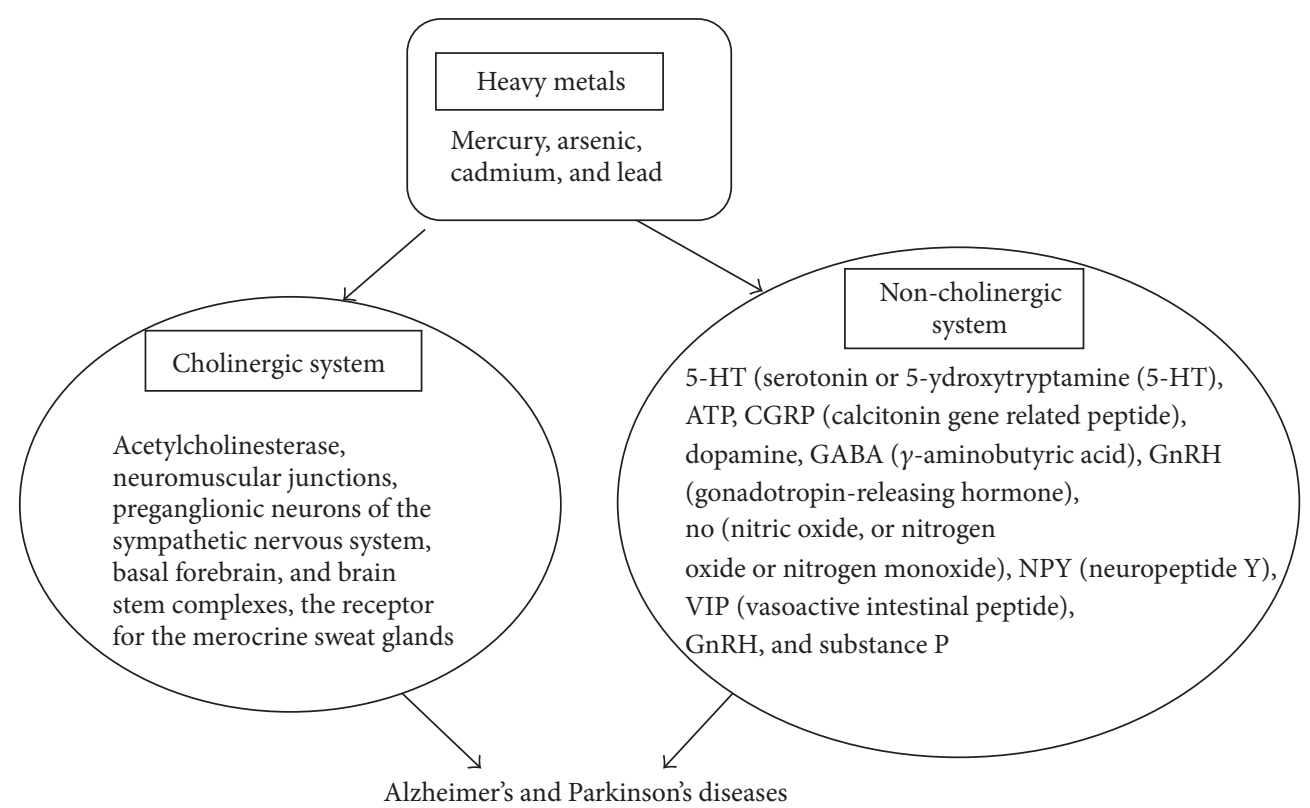

FIGURE 1: Effect of heavy metals on the cholinergic and noncholinergic systems associated to Alzheimer's and Parkinson's diseases.

the current account of phytochemicals mediated protection from neurotoxicity induced by certain heavy metals in animals including humans.

\section{Heavy Metals Influencing Cholinergic and Noncholinergic Systems}

Heavy metals are shown to adversely influence the functions of cholinergic and noncholinergic systems. The association of such impact of heavy metals with generation of Alzheimer's and Parkinson's diseases has been documented. A cholinergic system, the most significant modulators of neurotransmission systems in the brain, regulates physiological and cognitive functions such as memory, learning, neuronal development, and differentiation $[4,5]$. Any substance or ligands having ability to produce, alter, or release acetylcholine or mimic its functions at the specific acetylcholine receptor type is categorized as a cholinergic. Similarly, any receptor or synapse using acetylcholine as a neurotransmitter is cholinergic. The parasympathetic nervous system or the preganglionic neurons of the sympathetic nervous system, neuromuscular junctions, the basal forebrain, brain stem, and the receptor for the merocrine sweat glands are also cholinergic, since acetylcholine is involved in their functions. On the other hand, the noncholinergic system involving a nonnoradrenergic, noncholinergic neurotransmitter (NANC) belongs to the autonomic nervous system (ANS) and includes serotonin or 5-hydroxytryptamine (5-HT), ATP, Calcitonin gene related peptide (CGRP), Dopamine, $\boldsymbol{\gamma}$-aminobutyric acid (GABA), Gonadotropin-releasing hormone $(\mathrm{GnRH})$, nitric oxide, or nitrogen oxide or nitrogen monoxide (NO), Neuropeptide Y (NPY), Vasoactive intestinal peptide (VIP), and substance $\mathrm{P}$. The heavy metals may form complexes with these cellular factors containing oxygen, nitrogen, or sulphur and the resultant chemical species may produce toxicity which might lead to the modification in protein's structure or change in enzyme system, cellular dysfunction, and finally death of the cell. The effects of heavy metals on the cholinergic and noncholinergic systems are summarized in Figure 1.

2.1. Mercury $(\mathrm{Hg})$. All the natural forms of mercury (physical and chemical forms) can produce toxic effect at high doses. There are so many different forms of mercury which includes inorganic mercurous (Hg II), elemental mercury vapour $(\mathrm{Hg})$, mercuric (Hg III), and organic mercuric compounds [33] which have toxic effects in organs like brain, lungs, and kidney [34]. Natural mercury is present in liquid form when its oxidation state is zero. It is categorized in transition metal element in modern periodic table and is highly reactive and toxic. The chemistry of mercury, its chemical types, their metabolic transformations in different organs, varied toxic effects in mammalian systems, and possible reaction mechanisms have been recently reviewed by Sharma et al. (2014) [2]. The toxicity of mercury is known to be mediated by its binding with the thiol group of cellular proteins and enzymes which disrupts the cellular physiology in brain and other organs. The pathophysiology of mercury toxicity relates with the exposure of an individual by all the three forms (solid, liquid, and gas) of this heavy metal. Elemental mercury crosses the blood brain barrier (BBB) readily where it concentrates in neuronal dense bodies of lysosomes and finally leads to neurotoxicity. The symptoms of mercury toxicity include gastrointestinal disorders, headache, memory loss, depression, hypertension, and neuromuscular pains in both adults and children. The therapy of mercury poisoning has been advised to be done with different compounds including 2,3-dimercapto-1-propanesulfonic acid (DMPS), D-penicillamine (DPCN), dimercaprol (BAL), 
TABLE 1: Phytochemicals as antidotes to heavy metals induced toxicity.

\begin{tabular}{|c|c|c|c|}
\hline Phytochemicals & Sources & Protective functions & References \\
\hline Allicin & Garlic & $\begin{array}{l}\text { Reduces arsenic induced oxidative and arsenic toxicity } \\
\text { by complex formation. }\end{array}$ & {$[6,7]$} \\
\hline Anthocyanin/flavonoids & $\begin{array}{l}\text { Cherry, grapes, and } \\
\text { berries }\end{array}$ & $\begin{array}{l}\text { Anthocyanin protects against Cd-induced oxidative } \\
\text { stress. } \\
\text { Anthocyanin appears to effectively diminish } \mathrm{Pb} \\
\text { induced oxidative stress. }\end{array}$ & {$[8,9]$} \\
\hline Catechins & $\begin{array}{l}\text { Tea, cocoa, peach, } \\
\text { and berries }\end{array}$ & $\begin{array}{l}\text { Catechin inhibits Cd absorption and normalises bone } \\
\text { metabolic disorders through the bone mineral density, } \\
\text { bone mineral content, and bone calcium content. } \\
\text { Catechin protects hepatic cell membrane fluidity, } \\
\text { increases cell viability, and modulates oxidative stress. }\end{array}$ & {$[10,11]$} \\
\hline Curcumin & Turmeric & $\begin{array}{l}\text { Curcumin protects against } \mathrm{Cd} \text {-induced lipid } \\
\text { peroxidation. } \\
\text { Curcumin binds } \mathrm{Pb} \text { to form an excretable complex, } \\
\text { reducing neurotoxicity and nephrotoxicity. }\end{array}$ & [12-15] \\
\hline Naringenin & $\begin{array}{l}\text { Orange, grapefruit, } \\
\text { and tomato }\end{array}$ & $\begin{array}{l}\text { Naringenin quenches free radicals, recovers } \\
\text { antioxidant enzyme activity, and chelates Cd. }\end{array}$ & {$[16]$} \\
\hline$\gamma$-Oryzanol & Rice & $\begin{array}{l}\gamma \text {-Oryzanol reduces the testicular Cd concentration, } \\
\text { improves } \delta \text {-aminolevulinic acid dehydratase (ALAD) } \\
\text { activity, and prevents lipid peroxidation. }\end{array}$ & {$[17]$} \\
\hline Quercetin & $\begin{array}{l}\text { Onion, tomato and } \\
\text { radish olive oil, red } \\
\text { wine, tea, and so } \\
\quad \text { forth }\end{array}$ & $\begin{array}{l}\text { Induces the expression of endothelial nitric oxide } \\
\text { synthase (eNOS), inducible nitric oxide synthase } \\
\text { (iNOS), and cyclooxygenase- } 2 \text { (COX-2). Quercetin } \\
\text { modulates the mitogen-activated protein kinases } \\
\text { (MAPKs) and nuclear factor kappa B (NF- } \kappa \text { B) } \\
\text { signalling pathway and forms excretable complex with } \\
\text { Pb hydroxyl and superoxide groups scavenge radicals, } \\
\text { whereas the phenolic groups act as possible chelating } \\
\text { sites. }\end{array}$ & {$[18-23]$} \\
\hline Phenolics & $\begin{array}{l}\text { Coriander, fruits, } \\
\text { vegetables, and tea }\end{array}$ & Act as antioxidants. & {$[13,24,25]$} \\
\hline Phycocyanobilin & $\begin{array}{l}\text { Cyanobacteria } \\
\text { (Spirulina and } \\
\text { Chlorella) }\end{array}$ & Probably acting as antioxidants. & {$[26,27]$} \\
\hline Puerarin & $\begin{array}{l}\text { Pueraria mirifica } \\
\text { plant }\end{array}$ & $\begin{array}{l}\text { Puerarin modulates the phosphoinositide-3-kinase } \\
\text { (PI3K)/protein kinase B (Akt)/endothelial nitric oxide } \\
\text { synthase (eNOS) pathway, reduces reactive oxygen } \\
\text { species, and protects against DNA damage and } \\
\text { apoptosis. }\end{array}$ & {$[22,28]$} \\
\hline $\begin{array}{l}\text { Vitamins } \mathrm{A}(\beta- \\
\text { carotenes), B1, B6, C, } \\
\text { and } \mathrm{E}\end{array}$ & Nigella sativa & Act as antioxidants. & {$[29-32]$} \\
\hline
\end{tabular}

and antioxidants such as $\mathrm{N}$-acetylcysteine (NAC) and glutathione. The treatment of mercury intoxication is mainly managed by chelation therapy for a long period of time. However, some plant based principles have also been found to exhibit immense potential to either protect or recover from mercury induced toxicity in humans and animals. The ameliorative/protective properties of some phytochemicals have been explained in a different section and Table 1.

2.2. Cadmium $(\mathrm{Cd})$. Cadmium as an important member of the last d-orbital group in modern periodic table has similar chemical properties, respectively, with zinc and mercury preferably containing oxidation state +2 and low melting point. Cadmium poisoning takes place due to exposure through inhalation of cadmium fumes in the atmospheres and intake of food, water, and tobacco. Exposure to cadmium leads to occurrence of several ailments such as anaemia, osteoporosis, blood, brain, and skin related diseases. Exposure to $\mathrm{Cd}$ is reported to cause malfunctioning of fetus which includes ablephary, club foot, exencephaly, micrognathia, and microphthalmia. Severe exposure to calcium may harm both the fetus and the mother by enhancing the numbers of micronucleated polychromatic erythrocytes (MNPE) and micronucleated normochromatic erythrocytes (MNNE) [35]. Cadmium is known to produce free radicals and oxidative stress which is one of the mechanisms of its toxicity [36] as 
it combines with thiol groups of enzymes involved in antioxidant mechanisms and inactivates them. Since Cadmium can replace magnesium and calcium in certain biological systems [37], it adversely influences the concerned biological processes. Cadmium exposure may also alter DNA repair activity [38]. Cadmium intoxicated individual may suffer from neurotoxicity and respiratory, circulatory, excretory, and gastrointestinal disorders. Chronic exposure of cadmium results into appearance of certain clinical symptoms such as headache, sleep disorders and memory deficits, increased salivation, throat choking, and renal and hepatic failures, which are associated to the alterations in metabolism of neurotransmitters particularly of GABA and serotonin. Similar to mercury, the treatment of cadmium poisoning involves application of antioxidants, chelators [2], and phytochemicals as described in a separate section as well as in Table 1.

2.3. Arsenic (As). Arsenic exists in trivalent arsenite (As III) and pentavalent (As V) arsenate forms. Arsenic accumulates in the body through seafood, inhalation, and absorption through skin and causes disorders in GI tract, neurotransmission, blood circulation system, and respiratory system. Arsenic exposure is known to produce free radicals and hence generates oxidative stress. It adversely influences the activities and levels of antioxidative elements such as superoxide dismutase (SOD), catalase (CAT), glutathione peroxidase (GPx), heme oxygenase-1 (HO-1), and the nonenzymatic factors such as sulfhydryl group containing peptides and proteins in human systems. Arsenic toxicity adversely influences Krebs cycle and oxidative phosphorylation leading to the depletion of energy as well as rapid depletion of thiol group containing critical peptides/proteins [39]. Arsenic poisoning is characterized by burning and numbness in the hands and feet and alterations in functions of neurotransmission and cardiovascular systems. In particular, in the patients with diabetes mellitus, arsenic toxicity may be considered as a major contributor to vascular and neurological complications $[40,41]$. Normal value for urine is less than $50 \mathrm{mg} / \mathrm{L}$ and whole blood arsenic level is usually less than $1 \mathrm{mg} / \mathrm{dL}$ [39]. The treatment of arsenic intoxication is carried out mainly by chelation therapy using dimercaprol or succimer $(2,3-$ dimercaptosuccinic acid, DMSA) and aqueous garlic extract [42]. However, some phytochemicals have been found to be very useful in combating arsenic toxicity as displayed in Table 1 and in the following section.

2.4. Lead $(\mathrm{Pb})$. Lead being used in batteries, metal products, and medical appliances has been found to be an important cause of concern of heavy metal toxicity in biological systems exposed to it [43]. According to the Centres for Disease Control and Prevention (CDC)-USA, a blood lead level (BLL) of $10 \mu \mathrm{g} / \mathrm{dL}$ or above is a cause for concern. Lead mediated toxicity includes varied physiological, biochemical, and behavioural dysfunctions in human's peripheral and central nervous systems, blood circulatory, cardiovascular, excretory, metabolic, and reproductive systems [44]. It causes neurotoxicity in general but significantly reduces paediatric cognitive functions [45]. The prime mechanism of lead mediated neurotoxicity is associated with the production of excess free radical species and oxidative stress which has potential to cause perturbations in the brain $[1,46,47]$. Since Lead efficiently crosses the BBB [48] and it easily substitutes calcium ions, interferes with the regulatory action of calcium on brain cells, and disrupts its intracellular activities [48], the pathogenic symptoms of lead toxicity include hypertension, cognitive deficit [49], anaemia, peripheral motor neuropathy, and gastrointestinal disorders. The chronic lead toxicity (>70 mg/dL) in children may lead to frequent occurrence of coma, seizures, and altered mental status. The effective treatment of lead toxicity includes using preventive measures, chelation therapy, and application of some herbal preparations (Table 1).

\section{Phytochemicals Used in Amelioration of Heavy Metals Induced Neurotoxicity}

Despite the fact that the phytochemicals contain plenty of flavonoids and polyphenols like antioxidants, they may also help ameliorate the heavy metals mediated toxicity in human and other animals. The oral administration of Arthrospira maxima (Spirulina) has been shown to significantly reduce cadmium mediated genotoxic effects which has been corroborated to some extent with the antioxidant potential of the aforesaid algae [35]. Very recently, cadmium induced arterial and cardiac injuries could be significantly reduced by introducing dietary soybean supplementation in diet [48]. Mohammed et al. (2014) [49] have indicated that Nigella sativa seed oil contains strong antioxidant properties and hence may protect vital organs (brain and kidney) of the body from oxidative damages. They have proposed that Nigella sativa seed oil and the virgin olive oils can be used by many workers employed in cement factories wherein $\mathrm{Cd}$ is so frequently liberated in the environment. The phytochemicals such as vitamin $\mathrm{C}$, vitamin $\mathrm{E}$, phycocyanobilin, and carotenes are presented into some cyanobacterial species such as Spirulina and Chlorella which have been found to impart protection to rats exposed to lead and cadmium [26, 27, 30, 31].

The application of vitamin $\mathrm{E}$ has demonstrated that its administration along with cadmium caused notable reduction in accumulation of this metal in different key tissues (kidney, liver, and blood) of the body [50, 51]. Similar to the antioxidative role of fat soluble vitamin $\mathrm{E}$, the water soluble vitamins ( $\mathrm{C}, \mathrm{B} 1$, and B6) have been found to protect the organs of rats from cadmium and lead toxicities [29, 32]. When vitamins $\mathrm{C}$ and $\mathrm{E}$ were administered together in cadmium intoxicated rats, the level of oxidative stress was sharply reduced $[52,53]$. In one of the similar experiments when vitamin $\mathrm{E}$ was supplemented to $\mathrm{Pb}$ treated erythrocytes, the activity of $\delta$-aminolevulinic dehydratase and lipid oxidation was significantly reduced [54]. $\beta$-Carotene, a redorange pigment, fat soluble organic compound abundant in plants and fruits, has been found to serve as a precursor of vitamin A (retinol). It has been reported to be associated with increased rate of lung cancer among smokers [55]. 
Using garlic extract, some workers were able to demonstrate reduction in cadmium and lead mediated mitochondrial injury and apoptosis in tissue culture models as well as neural, hepatic, renal, and haematic damage in rats [5658]. Garlic is shown to possess higher antioxidant potential than onion [59] which may be associated with the presence of allicin [7]. Aslani et al. (2010) [6] have shown that the administration of the mixture of garlic extract and dimercaptosuccinic acid (DMSA) may be able to very effectively ameliorate the rats suffering from lead poisoning. In addition to many health benefits, garlic also acts as a booster of immunity and contains antiaging substance(s) [60]. The extract of garlic has been reported to act as a potential antidote to the toxic effects of sodium arsenite $[61,62]$. It is thought that the protective effect of garlic from arsenic toxicity is rendered through the thiosulfur components present in the extract which would be making some stable chemical complexes after reacting with arsenic chemical species and inactivating arsenic mediated toxicity [19]. The existing information suggests that presence of various components in the aqueous extracts of garlic in general and allicin in particular may participate in chelation of arsenic $[63,64]$. The reduction in the toxicity induced by arsenic has been achieved by the coadministration of plant extracts, such as Allium sativum, Aloe vera barbadensis, Centella asiatica, curcumin, and Hippophae rhamnoides as recorded by evaluating hematological, renal, and hepatic parameters in experimental animals [19, 65-69]. In order to mitigate the toxicity of arsenic, not many plants have been explored to be used as a medicine.

However, the leaf extracts of Annona muricata have been found to have potential to significantly reduce arsenic mediated neurotoxicity [70-72]. The methanolic extract of the leaves of A. muricata was found to exhibit higher activity than the aqueous extract. They observed a dose-dependent decrease in arsenic toxicity. These authors have also indicated that tea extract could also be useful in arsenic poisoning cases to reduce the toxicity. $H$. rhamnoides is a rich source of vitamins A, C, and E; carotenoids and organic acids which gives positive effects on arsenic induced toxicity have been attributed to the presence of high content of antioxidant substances $[67,69]$.

The quercetin $\left(3^{\prime}, 3,4^{\prime}, 5,7\right.$-pentahydroxyflavone), a dietary flavonoid, is found in fruits and vegetables, olive oil, red wine, and tea $[18,19]$. It has been observed to contain free radical quenching activity which scavenges free radicals (Hertog et al., 1995) [18] induced by arsenic exposure when administered either alone or in combination with a thiol chelator $[73,74]$. It has been observed that a nanocapsulated drug delivery system of Quercetin can provide better medication to prevent arsenic induced damage than bulk administration of Quercetin [73, 75]. The extracts from a few other traditional medicinal plants such as Moringa oleifera, A. barbadensis, and C. asiatica have also been found to offer beneficial effects by protecting the vital organs of the body probably by reducing oxidative stress $[66,68,76]$ and depletion of arsenic concentration in tissue [68] and through the interactions of phytochemicals with cysteineand methionine-rich proteins $[73,76,77]$.
Tomato extract has been shown to reduce bioaccumulation of heavy metals [78] and acts as a strong antioxidant and protectant from cadmium and lead mediated toxicities in rats $[79,80]$. This property of tomato may be associated to the presence of certain metal chelating proteins and phytochelatins [81]. Some Indian spices such as coriander is shown to contain phenolic acid compounds like caffeic acid, chlorogenic acid, vanillic acid, pcoumaric acid, ferulic acid (cis and trans form) [24, 25], and curcumin \{1,7-bis (4-hydroxy-3-methoxyphenyl)-1,6heptadiene-3,5-Dione\} (diferuloyl methane) isolated from turmeric has anti-inflammatory and antioxidant properties [82] which enables it to protect the cadmium exposed rats from nephrotoxicity [13]. During a field trial conducted in West Bengal, curcumin was derived from turmeric [12].

For a very long time, the antioxidative properties of tea have been known [83-85]. The catechins present in green tea and the flavonoids and phenols of curry leaves as well as fruits (grapes) have been demonstrated to exhibit similar protective effects $[86,87]$ in the cases of lead and cadmium poisoning. The major green tea polyphenols with antioxidant properties may include (-)-epigallocatechin-3-gallate (EGCG), (-)-epicatechin-3-gallate (ECG), (-)-epigallocatechin (EGC), (-)-epicatechin (EC), (+)-gallocatechin (GC), and (+)-catechin $[83,85]$.

Chinthana and Ananthi (2012) [88] have reported that the neurotoxicity induced by lead in albino mice could be significantly reduced by oral administration of extract of $S$. nigrum and S. trilobatum leaves for 30 days. They observed substantial increase in the activities of antioxidant enzymes such as SOD, CAT, GPx, and reduced lipid peroxidation. $S$. nigrum is a weed and some species of it may be toxic to humans and animals. This plant is widely used as a traditional medicine [89]. Similar observations have been recorded by Zaidi et al. (2014) [90] when they evaluated the prophylactic or curative antioxidant efficacy of crude extract and the active constituent of $S$. nigrum leaves in the brain of stressed rat.

A summary of the key phytochemicals isolated from different plant sources and characterised for protection from heavy metals mediated neurotoxicity are presented in Table 1. A graphical sketch of protection offered by dietary supplements against the heavy metals induced alterations in biochemical and physiological functions of the body is displayed in Figure 2.

\section{Conclusion}

The heavy metals exhibit the ability to induce oxidative stress by generating ROS. Oxidative stress due to heavy metals is the outcome of a negative shift of the balance between the production of ROS and the ability of the biological systems to readily counteract the ROS mediated damage or repair of it rapidly. The heavy metals toxicity is caused either by their direct binding with thiol groups of the proteins/enzymes thereby causing perturbations in their threedimensional conformations or by replacing the divalent metal ions from their catalytic pocket which are essentially required by concerned proteins/enzymes as cofactors for their optimal activity. In either of these situations, these 


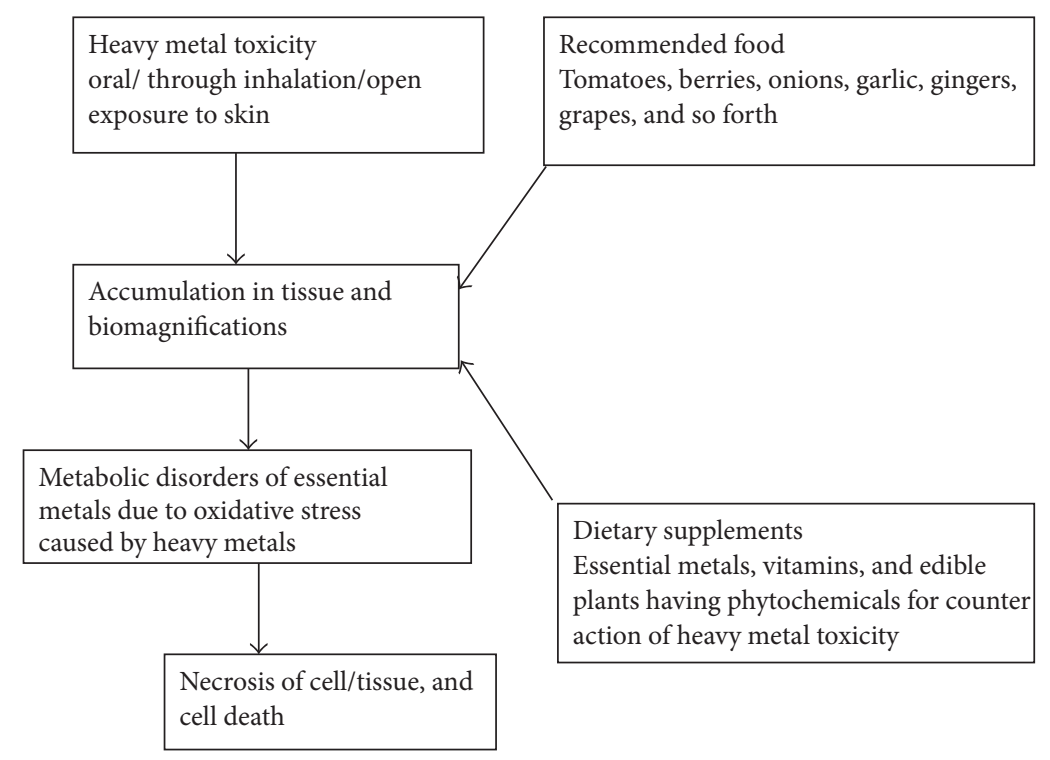

FIGURE 2: Impact of heavy metals on human system.

biomolecules tend to lose their native characteristics due to unfolding or denaturation and then their functions are greatly compromised, which lead to serious bearings on to their biological activity and finally the cellular health. All forms of life maintain a reducing environment within their cells. This reducing environment is preserved by enzymes that maintain the reduced state through a constant input of metabolic energy. Disturbances in this normal redox state by heavy metals can cause toxic effects indirectly through the production of peroxides and free radicals that induce oxidative stress, which is responsible for the damage of several key components of the cells, including proteins, lipid, and DNA. The amelioration of neurotoxicity induced by certain heavy metals by herbal principles is of great significance as they are cost effective and highly active and lead to no side effects. In addition to them, the application of certain vitamins and a number of chelating organic molecules is being tried with the expectation that they would make coordinate complexes with these heavy metals and help remove them making the affected organs or tissues free from metal's burden and toxicity. Although coadministration of antioxidants (natural, herbal, or synthetic) or with other chelating agents has shown to improve removal of toxic metals from the system as well as clinical recoveries in animal models, still the in-depth clinical studies with preexisting or newer chelating agents are required to be done to reap real benefit with the least side effects. In case of humans, it is also important to find out the suitable dose and duration of treatment to decide the optimal therapeutic index for any of the drugs to be given in isolation or in different combinations. In conclusion, the present stage of knowledge about the impact of heavy metals in biological systems indicates the enhanced formation of free radicals and ROS or RNS or their intermediates causing neurotoxicity and other ailments and that could be efficiently managed by using different preparations from a number of traditional medicinal plants.

\section{Conflict of Interests}

The authors report no declarations of interests.

\section{Acknowledgments}

Vivek Kumar Gupta and Shweta Singh are grateful to the University Grant Commission, New Delhi, for providing research fellowships for this work at the Department of Biochemistry, University of Allahabad, India. Nikhat Jamal Siddiqi gratefully thanks the Research Center, Female Center for Scientific and Medical Colleges, King Saud University, Riyadh, for the support.

\section{References}

[1] S. J. S. Flora, S. Chouhan, G. M. Kannan, M. Mittal, and H. Swarnkar, "Combined administration of taurine and monoisoamyl DMSA protects arsenic induced oxidative injury in rats," Oxidative Medicine and Cellular Longevity, vol. 1, no. 1, pp. 3945, 2008.

[2] B. Sharma, S. Singh, and N. J. Siddiqi, "Biomedical implications of heavy metals induced imbalances in redox systems," BioMed Research International, vol. 2014, Article ID 640754, 26 pages, 2014.

[3] M. Valko, H. Morris, and M. T. D. Cronin, "Metals, toxicity and oxidative stress," Current Medicinal Chemistry, vol. 12, no. 10, pp. 1161-1208, 2005.

[4] A. E. Power, "Muscarinic cholinergic contribution to memory consolidation: with attention to involvement of the basolateral amygdala," Current Medicinal Chemistry, vol. 11, no. 8, pp. 987996, 2004.

[5] V. Fodale, D. Quattrone, C. Trecroci, V. Caminiti, and L. B. Santamaria, "Alzheimer's disease and anaesthesia: implications for the central cholinergic system," British Journal of Anaesthesia, vol. 97, no. 4, pp. 445-452, 2006. 
[6] M. R. Aslani, V. Najarnezhad, and M. Mohri, "Individual and combined effect of meso-2,3-dimercaptosuccinic acid and allicin on blood and tissue lead content in mice," Planta Medica, vol. 76, no. 3, pp. 241-244, 2010.

[7] D. Shahsavani, H. Baghshani, and E. Alishahi, "Efficacy of allicin in decreasing lead $(\mathrm{Pb})$ accumulation in selected tissues of lead-exposed common carp (Cyprinus carpio)," Biological Trace Element Research, vol. 142, no. 3, pp. 572-580, 2011.

[8] E. Kowalczyk, A. Kopff, P. Fijałkowski et al., "Effect of anthocyanins on selected biochemical parameters in rats exposed to cadmium," Acta Biochimica Polonica, vol. 50, no. 2, pp. 543-548, 2003.

[9] A. A. El-Nekeety, A. A. El-Kady, M. S. Soliman, N. S. Hassan, and M. A. Abdel-Wahhab, "Protective effect of Aquilegia vulgaris (L.) against lead acetate-induced oxidative stress in rats," Food and Chemical Toxicology, vol. 47, no. 9, pp. 2209-2215, 2009.

[10] L. Chen, X. Yang, H. Jiao, and B. Zhao, "Tea catechins protect against lead-induced cytotoxicity, lipid peroxidation, and membrane fluidity in HepG2 cells," Toxicological Sciences, vol. 69, no. 1, pp. 149-156, 2002.

[11] J.-H. Choi, I.-K. Rhee, K.-Y. Park, K.-Y. Park, J.-K. Kim, and S.-J. Rhee, "Action of green tea catechin on bone metabolic disorder in chronic cadmium-poisoned rats," Life Sciences, vol. 73, no. 12, pp. 1479-1489, 2003.

[12] J. Biswas, D. Sinha, S. Mukherjee, S. Roy, M. Siddiqi, and M. Roy, "Curcumin protects DNA damage in a chronically arsenicexposed population of West Bengal," Human and Experimental Toxicology, vol. 29, no. 6, pp. 513-524, 2010.

[13] P. Singh, V. Sankhla, P. Mogra et al., "Protective effect of curcumin on cadmium-chloride induced nephrotoxicity in swiss albino mice," Journal of Herbal Medicine and Toxicology, vol. 4, no. 2, pp. 215-219, 2010.

[14] S. Daniel, J. L. Limson, A. Dairam, G. M. Watkins, and S. Daya, "Through metal binding, curcumin protects against lead- and cadmium-induced lipid peroxidation in rat brain homogenates and against lead-induced tissue damage in rat brain," Journal of Inorganic Biochemistry, vol. 98, no. 2, pp. 266-275, 2004.

[15] V. Eybl, D. Kotyzova, and J. Koutensky, "Comparative study of natural antioxidants-curcumin, reservetrol and melatonin-in cadmium-induced oxidative damage in mice," Toxicology, vol. 225, no. 2-3, pp. 150-156, 2006.

[16] J. Renugadevi and S. M. Prabu, "Naringenin protects against cadmium-induced oxidative renal dysfunction in rats," Toxicology, vol. 256, no. 1-2, pp. 128-134, 2009.

[17] C. C. Spiazzi, V. Manfredini, F. E. Barcellos da Silva et al., " $\gamma$ Oryzanol protects against acute cadmium-induced oxidative damage in mice testes," Food and Chemical Toxicology, vol. 55, pp. 526-532, 2013.

[18] M. G. L. Hertog, D. Kromhout, C. Aravanis et al., "Flavonoid intake and long-term risk of coronary heart disease and cancer in the Seven Countries Study," Archives of Internal Medicine, vol. 155, no. 4, pp. 381-386, 1995.

[19] S. J. S. Flora, A. Mehta, and R. Gupta, "Prevention of arsenicinduced hepatic apoptosis by concomitant administration of garlic extracts in mice," Chemico-Biological Interactions, vol. 177, no. 3, pp. 227-233, 2009.

[20] W. Banner Jr., M. Koch, D. M. Capin, S. B. Hopf, S. Chang, and T. G. Tong, "Experimental chelation therapy in chromium, lead, and boron intoxication with $\mathrm{N}$-acetylcysteine and other compounds," Toxicology and Applied Pharmacology, vol. 83, no. 1, pp. 142-147, 1986.
[21] A. I. Morales, C. Vicente-Sánchez, M. Jerkic et al., "Effect of quercetin on metallothionein, nitric oxide synthases and cyclooxygenase-2 expression on experimental chronic cadmium nephrotoxicity in rats," Toxicology and Applied Pharmacology, vol. 210, no. 1-2, pp. 128-135, 2006.

[22] C.-M. Liu, Y.-Z. Sun, J.-M. Sun, J.-Q. Ma, and C. Cheng, "Protective role of quercetin against lead-induced inflammatory response in rat kidney through the ROS-mediated MAPKs and NF- $\kappa$ B pathway," Biochimica et Biophysica Acta, vol. 1820, no. 10, pp. 1693-1703, 2012.

[23] C.-M. Liu, G. H. Zheng, Q. L. Ming, J. M. Sun, and C. Cheng, "Protective effect of quercetin on lead-induced oxidative stress and endoplasmic reticulum stress in rat liver via the IRE1/JNK and PI3K/Akt pathway," Free Radical Research, vol. 47, no. 3, pp. 192-201, 2013.

[24] V. S. Nambiar, M. Daniel, and P. Guin, "Characterization of polyphenols from coriander leaves (Coriandrum sativum), red amaranthus (A. paniculatus) and green amaranthus $(A$. frumentaceus) using paper chromatography and their health implications," Journal of Herbal Medicine and Toxicology, vol. 4, no. 1, pp. 173-177, 2010.

[25] U. Rajeshwari and B. Andallu, "Medicinal benefits of coriander (Coriandrum sativum L)," Spatula DD, vol. 1, no. 1, pp. 51-58, 2011.

[26] J.-Y. Shim and A.-S. Om, "Chlorella vulgaris has preventive effect on cadmium induced liver damage in rats," Molecular \& Cellular Toxicology, vol. 4, pp. 138-143, 2008.

[27] H. Yun, I. Kim, S.-H. Kwon, J.-S. Kang, and A.-S. Om, "Protective effect of Chlorella vulgaris against Lead-Induced oxidative stress in rat brains," Journal of Health Science, vol. 57, no. 3, pp. 245-254, 2011.

[28] J. Jungsukcharoen, B. A. Dhiani, W. Cherdshewasart, N. Vinayavekhin, P. Sangvanich, and C. Boonchird, "Pueraria mirifica leaves, an alternative potential isoflavonoid source," Bioscience, Biotechnology, and Biochemistry, vol. 78, no. 6, pp. 917-926, 2014.

[29] J. A. Simon and E. S. Hudes, "Relationship of ascorbic acid to blood lead levels," The Journal of the American Medical Association, vol. 281, no. 24, pp. 2289-2293, 1999.

[30] A. Amin, A. A. Hamza, S. Daoud et al., "Spirulina protects against cadmium-induced hepatotoxicity in rats," American Journal of Pharmacology and Toxicology, vol. 1, no. 2, pp. 21-25, 2006.

[31] J.-Y. Shim, H.-S. Shin, J.-G. Han et al., "Protective effects of Chlorella vulgaris on liver toxicity in cadmium-administered rats," Journal of Medicinal Food, vol. 11, no. 3, pp. 479-485, 2008.

[32] G. H. El-Sokkary and E. A. Awadalla, "The protective role of vitamin $\mathrm{C}$ against cerebral and pulmonary damage induced by cadmium chloride in male adult albino rat," Open Neuroendocrinology Journal, vol. 4, pp. 1-8, 2011.

[33] B. Hultberg, A. Andersson, and A. Isaksson, "Interaction of metals and thiols in cell damage and glutathione distribution: potentiation of mercury toxicity by dithiothreitol," Toxicology, vol. 156, no. 2-3, pp. 93-100, 2001.

[34] W. F. Fitzgerald and T. W. Clarkson, "Mercury and monomethylmercury: present and future concerns," Environmental Health Perspectives, vol. 96, pp. 159-166, 1991.

[35] N. Argüelles-Velázquez, I. Alvarez-González, E. MadrigalBujaidar, and G. Chamorro-Cevallos, "Amelioration of cadmium-produced teratogenicity and genotoxicity in mice given Arthrospira maxima (Spirulina) treatment," Evidence-Based 
Complementary and Alternative Medicine, vol. 2013, Article ID 604535, 8 pages, 2013.

[36] B. Halliwell and J. M. C. Gutteridge, Free Radicals in Biology and Medicine, Uarendon Press, Oxford, UK, 2nd edition, 1989.

[37] S. D. Lane, D. R. Cherek, O. V. Tcheremissine, L. M. Lieving, and C. J. Pietras, "Acute marijuana effects on human risk taking," Neuropsychopharmacology, vol. 30, no. 4, pp. 800-809, 2005.

[38] G. Bertin and D. Averbeck, "Cadmium: cellular effects, modifications of biomolecules, modulation of DNA repair and genotoxic consequences (a review)," Biochimie, vol. 88, no. 11, pp. 1549-1559, 2006.

[39] S. A. Stice, "Speciation, metabolism, toxicity and proteinbinding of different arsenic species in human cells," FIU Electronic Theses and Dissertations 1203, 2014.

[40] A. Parthiban, S. Vijayalingam, K. R. Shanmugasundaram, and R. Mohan, "Oxidative stress and the development of diabetic complications-antioxidants and lipid peroxidation in erythrocytes and cell membrane," Cell Biology International, vol. 19, no. 12, pp. 987-993, 1995.

[41] K. Yamanaka, F. Takabayashi, M. Mizoi et al., "Oral exposure of dimethyl arsenic acid, a main metabolite of inorganic arsenics, in mice leads to an increase in 8-Oxo- $2^{\prime}$-deoxyguanosine level, specially in the target organs for arsenic carcinogenesis," Biochemical and Biophysical Research Communications, vol. 287, pp. 66-70, 2001.

[42] B. Das, S. Mandal, and K. Chaudhuri, "Role of arginine, a component of aqueous garlic extract, in remediation of sodium arsenite induced toxicity in A375 cells," Toxicology Research, vol. 3, no. 3, pp. 191-196, 2014.

[43] C. Nava-Ruíz and M. Méndez-Armenta, "Cadmium, lead, thallium: occurrence, neurotoxicity and histopathological changes of the nervous system," in Pollutant Diseases, Remediation and Recycling, vol. 4 of Environmental Chemistry for a Sustainable World, pp. 321-349, Springer, 2013.

[44] I. Lancranjan, H. I. Popescu, O. Găvănescu, I. Klepsch, and M. Serbănescu, "Reproductive ability of workmen occupationally exposed to lead," Archives of Environmental Health, vol. 30, no. 8, pp. 396-401, 1975.

[45] G. Lockith, "Blood lead levels in children," Canadian Medical Association Journal, vol. 149, no. 2, pp. 139-142, 1993.

[46] S. J. Yiin and T. H. Lin, "Lead-catalyzed peroxidation of essential unsaturated fatty acid," Biological Trace Element Research, vol. 50, no. 2, pp. 167-172, 1995.

[47] B. O. Adegbesan and G. A. Adenuga, "Effect of lead exposure on liver lipid peroxidative and antioxidant defense systems of protein-undernourished rats," Biological Trace Element Research, vol. 116, no. 2, pp. 219-225, 2007.

[48] R. Brochin, S. Leone, D. Phillips et al., "The cellular effect of lead poisoning and its clinical picture," Georgetown Undergraduate Journal of Health Sciences, vol. 5, pp. 1-8, 2008.

[49] E. Mohammed, K. Hashem, and M. Rheim, "Biochemical study on the impact of Nigella sativa and virgin olive oils on cadmiuminduced nephrotoxicity and neurotoxicity in rats," Journal of Investigational Biochemistry, vol. 3, no. 2, pp. 71-78, 2014.

[50] S. K. Tandon, S. Singh, and M. Dhawan, "Preventive effect of vitamin E in cadmium intoxication," Biomedical and Environmental Sciences, vol. 5, no. 1, pp. 39-45, 1992.

[51] S. Nemmiche, D. Chabane-Sari, and P. Guiraud, "Role of $\alpha$ tocopherol in cadmium-induced oxidative stress in Wistar rat's blood, liver and brain," Chemico-Biological Interactions, vol. 170, no. 3, pp. 221-230, 2007.
[52] R. S. Gupta, E. S. Gupta, B. K. Dhakal, A. R. Thakur, and J. Ahnn, "Vitamin C and vitamin E protect the rat testes from cadmiuminduced reactive oxygen species," Molecules and Cells, vol. 17, no. 1, pp. 132-139, 2004.

[53] U. R. Acharya, M. Mishra, J. Patro, and M. K. Panda, "Effect of vitamins $\mathrm{C}$ and $\mathrm{E}$ on spermatogenesis in mice exposed to cadmium," Reproductive Toxicology, vol. 25, no. 1, pp. 84-88, 2008.

[54] A. Rendón-Ramirez, J. Cerbón-Solórzano, M. MaldonadoVega, M. A. Quintanar-Escorza, and J. V. Calderón-Salinas, "Vitamin-E reduces the oxidative damage on $\delta$-aminolevulinic dehydratase induced by lead intoxication in rat erythrocytes," Toxicology in Vitro, vol. 21, no. 6, pp. 1121-1126, 2007.

[55] F. M. El-Demerdash, M. I. Yousef, F. S. Kedwany, and H. H. Baghdadi, "Cadmium-induced changes in lipid peroxidation, blood hematology, biochemical parameters and semen quality of male rats: protective role of vitamin $\mathrm{E}$ and $\beta$-carotene," Food and Chemical Toxicology, vol. 42, no. 10, pp. 1563-1571, 2004.

[56] V. Sharma, A. Sharma, and L. Kansal, "The effect of oral administration of Allium sativum extracts on lead nitrate induced toxicity in male mice," Food and Chemical Toxicology, vol. 48, no. 3, pp. 928-936, 2010.

[57] A. O. Lawal and E. M. Ellis, "The chemopreventive effects of aged garlic extract against cadmium-induced toxicity," Environmental Toxicology and Pharmacology, vol. 32, no. 2, pp. 266-274, 2011.

[58] A. Sadeghi, A. E. Bideskan, F. Alipour, A. Fazel, and H. Haghir, "The effect of ascorbic acid and garlic administration on leadinduced neural damage in rat offspring's hippocampus," Iranian Journal of Basic Medical Sciences, vol. 16, no. 2, pp. 157-164, 2013.

[59] N. Benkeblia, "Free-radical scavenging capacity and antioxidant properties of some selected onions (Allium cepa L.) and garlic (Allium sativum L.) extracts," Brazilian Archives of Biology and Technology, vol. 48, no. 5, pp. 753-759, 2005.

[60] K. Rahman, "Garlic and aging: new insights into an old remedy," Ageing Research Reviews, vol. 2, no. 1, pp. 39-56, 2003.

[61] T. Das, A. Roychoudhury, A. Sharma, and G. Talukder, "Modification of clastogenicity of three known clastogens by garlic extract in mice in vivo," Environmental and Molecular Mutagenesis, vol. 21, no. 4, pp. 383-388, 1993.

[62] A. RoyChoudhury, T. Das, A. Sharma, and G. Talukder, "Dietary garlic extract in modifying clastogenic effects of inorganic arsenic in mice: two-generation studies," Mutation Research/Environmental Mutagenesis and Related Subjects, vol. 359, no. 3, pp. 165-170, 1996.

[63] H. Amagase, B. L. Petesch, H. Matsuura, S. Kasuga, and Y. Itakura, "Intake of garlic and its bioactive components," Journal of Nutrition, vol. 131, no. 3, 2001.

[64] R. Chowdhury, A. Dutta, S. R. Chaudhuri, N. Sharma, A. K. Giri, and K. Chaudhuri, "In vitro and in vivo reduction of sodium arsenite induced toxicity by aqueous garlic extract," Food and Chemical Toxicology, vol. 46, no. 2, pp. 740-751, 2008.

[65] H. Tiwari and M. V. Rao, "Curcumin supplementation protects from genotoxic effects of arsenic and fluoride," Food and Chemical Toxicology, vol. 48, no. 5, pp. 1234-1238, 2010.

[66] R. Gupta and S. J. S. Flora, "Protective value of Aloe vera against some toxic effects of arsenic in rats," Phytotherapy Research, vol. 19, no. 1, pp. 23-28, 2005.

[67] R. Gupta and S. J. S. Flora, "Therapeutic value of Hippophae rhamnoides L. against subchronic arsenic toxicity in mice," Journal of Medicinal Food, vol. 8, no. 3, pp. 353-361, 2005. 
[68] R. Gupta and S. J. S. Flora, "Effect of Centella asiatica on arsenic induced oxidative stress and metal distribution in rats," Journal of Applied Toxicology, vol. 26, no. 3, pp. 213-222, 2006.

[69] R. Gupta and S. J. S. Flora, "Protective effects of fruit extracts of Hippophae rhamnoides L. against arsenic toxicity in Swiss albino mice," Human and Experimental Toxicology, vol. 25, no. 6, pp. 285-295, 2006.

[70] K. Jomova, Z. Jenisova, M. Feszterova et al., "Arsenic: toxicity, oxidative stress and human disease," Journal of Applied Toxicology, vol. 31, no. 2, pp. 95-107, 2011.

[71] K. Sárközi, A. Papp, E. Horváth et al., “Green tea and vitamin $\mathrm{C}$ ameliorate some neuro-functional and biochemical signs of arsenic toxicity in rats," Nutritional Neuroscience, 2014.

[72] V. C. George, D. R. Kumar, P. K. Suresh, and R. A. Kumar, "In vitro protective potentials of Annona muricata leaf extracts against sodium arsenite-induced toxicity," Current Drug Discovery Technologies, vol. 12, no. 1, pp. 59-63, 2015.

[73] D. Mishra and S. J. S. Flora, "Quercetin administration during chelation therapy protects arsenic-induced oxidative stress in mice," Biological Trace Element Research, vol. 122, no. 2, pp. 137147, 2008.

[74] K. Bhatt and S. J. S. Flora, "Oral co-administration of $\alpha$-lipoic acid, quercetin and captopril prevents gallium arsenide toxicity in rats," Environmental Toxicology and Pharmacology, vol. 28, no. 1, pp. 140-146, 2009.

[75] A. Ghosh, A. K. Mandal, S. Sarkar, S. Panda, and N. Das, "Nanoencapsulation of quercetin enhances its dietary efficacy in combating arsenic-induced oxidative damage in liver and brain of rats," Life Sciences, vol. 84, no. 3-4, pp. 75-80, 2009.

[76] R. Gupta, G. M. Kannan, M. Sharma, and S. J. S. Flora, "Therapeutic effects of Moringa oleifera on arsenic-induced toxicity in rats," Environmental Toxicology and Pharmacology, vol. 20, no. 3, pp. 456-464, 2005.

[77] R. Gupta, D. K. Dubey, G. M. Kannan, and S. J. S. Flora, "Concomitant administration of Moringa oleifera seed powder in the remediation of arsenic-induced oxidative stress in mouse," Cell Biology International, vol. 31, no. 1, pp. 44-56, 2007.

[78] C. R. Nwokocha, M. I. Nwokocha, I. Aneto et al., "Comparative analysis on the effect of Lycopersicon esculentum (tomato) in reducing cadmium, mercury and lead accumulation in liver," Food and Chemical Toxicology, vol. 50, no. 6, pp. 2070-2073, 2012.

[79] E. O. Salawu, A. A. Adeleke, O. O. Oyewo et al., "Prevention of renal toxicity from lead exposure by oral administration of Lycopersicon esculentum," Journal of Toxicology and Environmental Health Sciences, vol. 1, no. 2, pp. 22-27, 2009.

[80] J. Shi and M. Le Maguer, "Lycopene in tomatoes: chemical and physical properties affected by food processing," Critical Reviews in Food Science and Nutrition, vol. 40, no. 1, pp. 1-42, 2000.

[81] A. Tito, A. Carola, M. Bimonte et al., "A tomato stem cell extract, containing antioxidant compounds and metal chelating factors, protects skin cells from heavy metal-induced damages," International Journal of Cosmetic Science, vol. 33, no. 6, pp. 543552, 2011.

[82] A. Barzegar and A. A. Moosavi-Movahedi, "Intracellular ROS protection efficiency and free radical-scavenging activity of curcumin," PLoS ONE, vol. 6, no. 10, Article ID e26012, 2011.

[83] B. A. Sutherland, R. M. A. Rahman, and I. Appleton, "Mechanisms of action of green tea catechins, with a focus on ischemiainduced neurodegeneration," The Journal of Nutritional Biochemistry, vol. 17, no. 5, pp. 291-306, 2006.
[84] E. A. Hamed, A.-R. M. A. Meki, and N. A. Abd El-Mottaleb, "Protective effect of green tea on lead-induced oxidative damage in rat's blood and brain tissue homogenates," Journal of Physiology and Biochemistry, vol. 66, no. 2, pp. 143-151, 2010.

[85] G. Kaushik, S. Satya, and S. N. Naik, "Green tea: protective action against oxidative damage induced by xenobiotics," Mediterranean Journal of Nutrition and Metabolism, vol. 4, no. 1, pp. 11-31, 2011.

[86] E. Mitra, A. K. Ghosh, D. Ghosh et al., "Protective effect of aqueous Curry leaf (Murraya koenigii) extract against cadmiuminduced oxidative stress in rat heart," Food and Chemical Toxicology, vol. 50, no. 5, pp. 1340-1353, 2012.

[87] V. C. Pires, A. P. B. Gollücke, D. A. Ribeiro, L. Lungato, V. D’Almeida, and O. Aguiar Jr., "Grape juice concentrate protects reproductive parameters of male rats against cadmium-induced damage: a chronic assay," British Journal of Nutrition, vol. 110, no. 11, pp. 2020-2029, 2013.

[88] P. Chinthana and T. Ananthi, "Protective effect of Solanum nigrum and Solanum trilobatum aqueous leaf extract on lead induced neurotoxicity in albino mice," Journal of Chemical and Pharmaceutical Research, vol. 4, no. 1, pp. 72-74, 2012.

[89] A. Mohy-Ud-Din, Z.-U. Khan, M. Ahmad, and M. A. Kashmiri, "Chemotaxonomic value of alkaloids in Solanum nigrum complex," Pakistan Journal of Botany, vol. 42, no. 1, pp. 653-660, 2010.

[90] S. K. Zaidi, M. N. Hoda, S. Tabrez et al., "Protective effect of Solanum nigrum leaves extract on immobilization stress induced changes in rat's brain," Evidence-Based Complementary and Alternative Medicine, vol. 2014, Article ID 912450, 7 pages, 2014. 

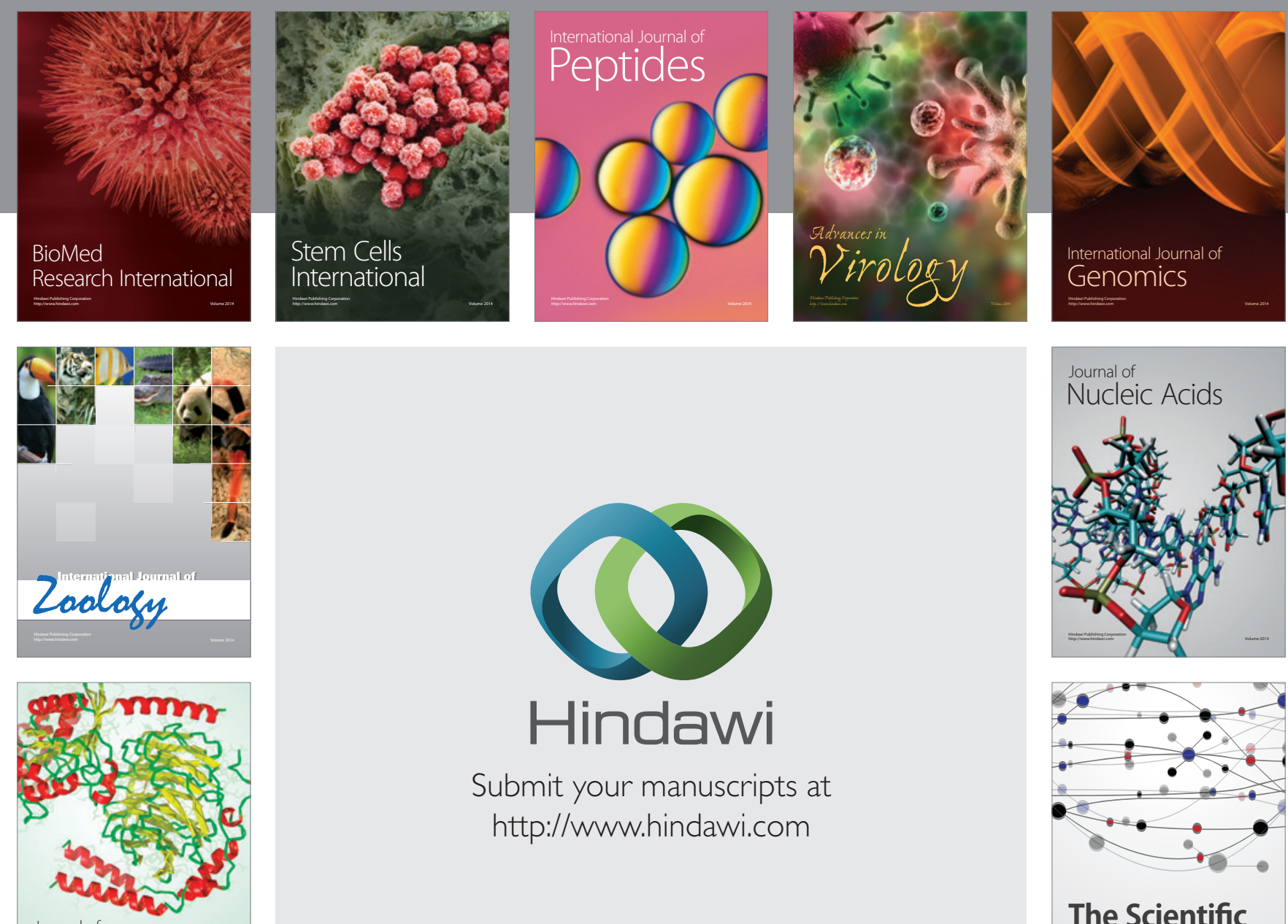

Submit your manuscripts at

http://www.hindawi.com

Journal of
Signal Transduction
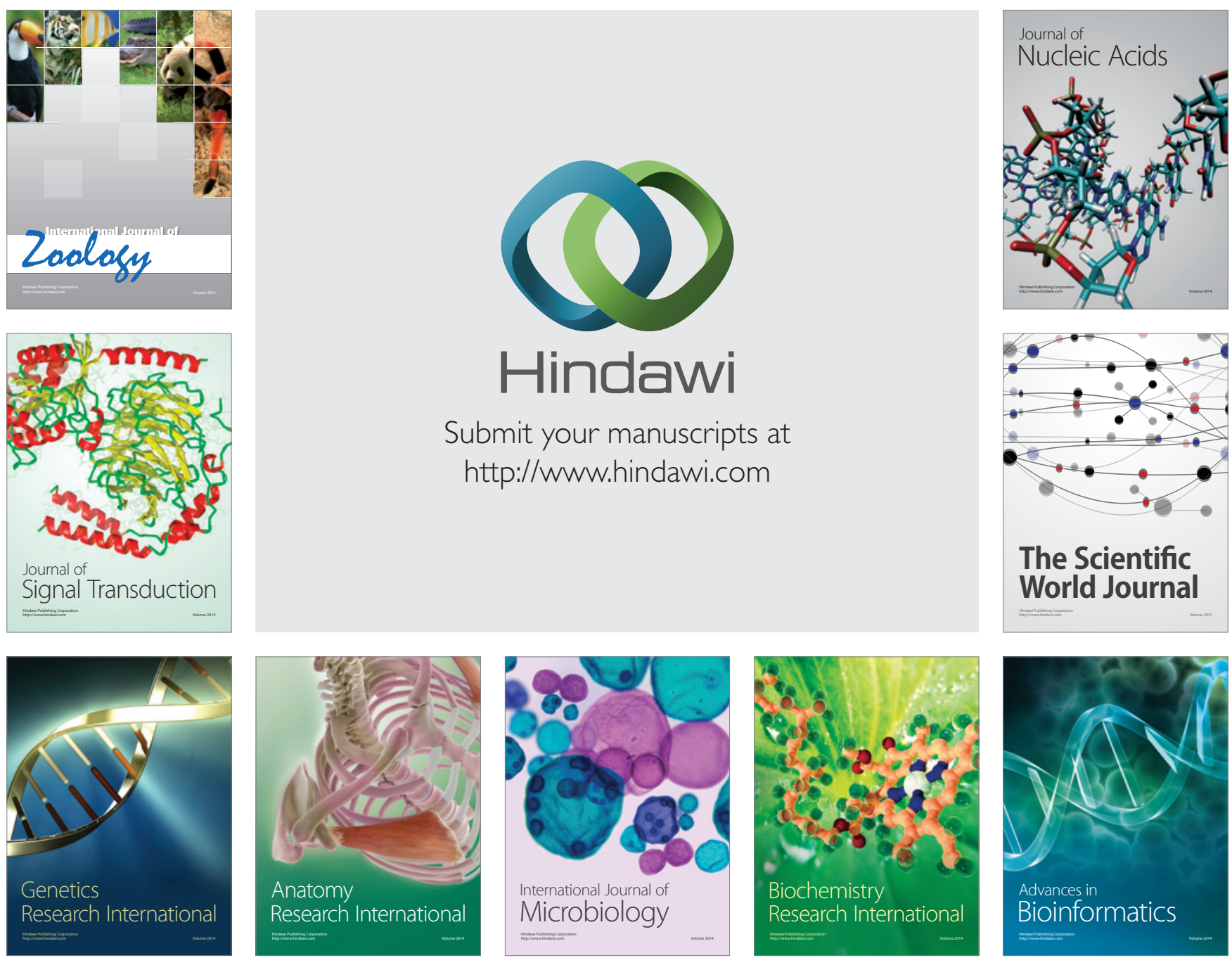

The Scientific World Journal
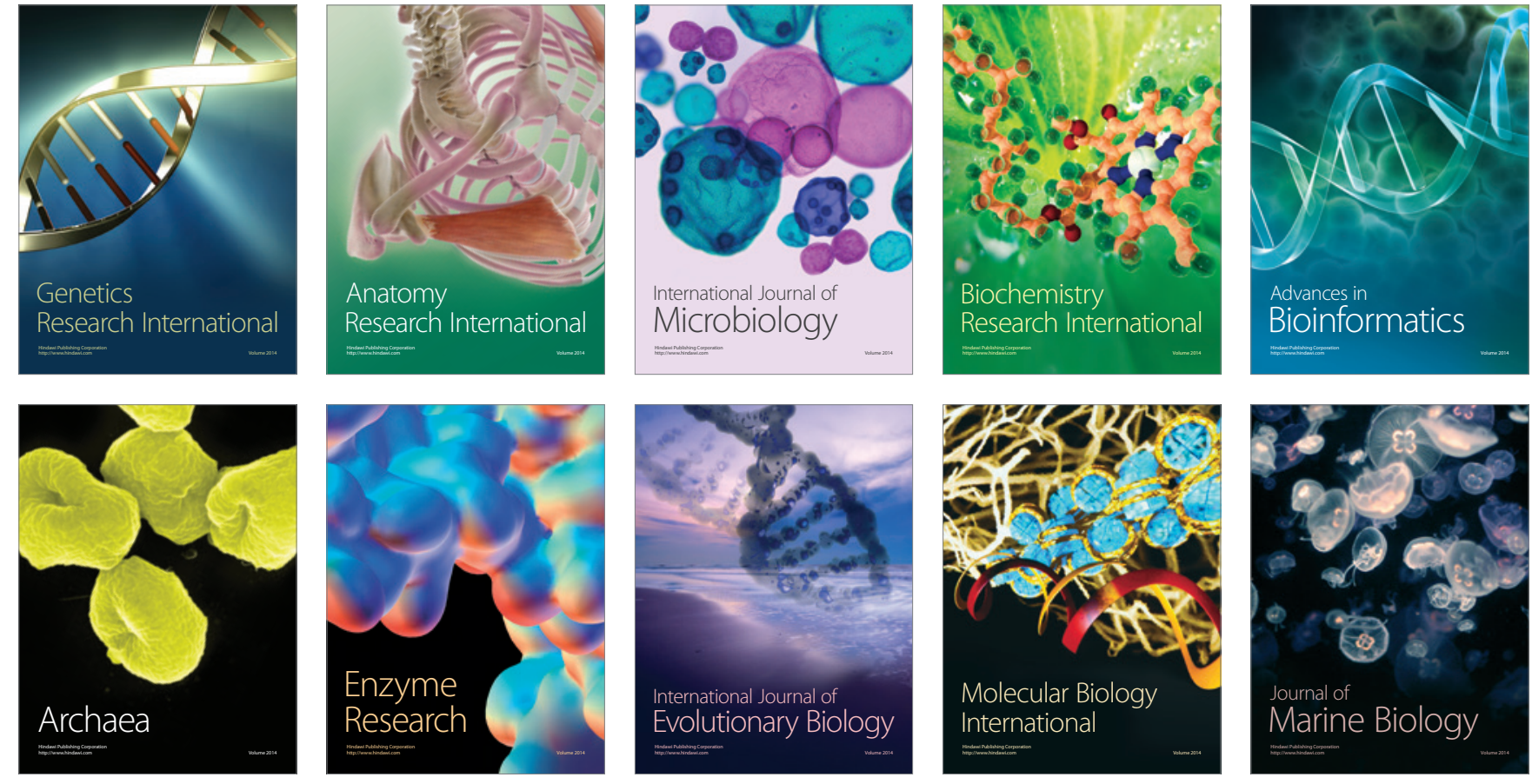